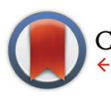

CrossMark

Cite this: Food Funct., 2017, 8, 964

\title{
Dietary polyacetylenes, falcarinol and falcarindiol, isolated from carrots prevents the formation of neoplastic lesions in the colon of azoxymethane- induced rats
}

\author{
Morten Kobaek-Larsen, ${ }^{\star a, b}$ Rime B. El-Houri, ${ }^{C}$ Lars P. Christensen, ${ }^{c}$ \\ Issam Al-Najami, ${ }^{a, b}$ Xavier Frettéc and Gunnar Baatrup ${ }^{a, b}$
}

\begin{abstract}
Falcarinol $(\mathrm{FaOH})$ and falcarindiol $(\mathrm{FaDOH})$ are found in many food plants of the Apiaceae family. Carrots are a major dietary source of these polyacetylenes. Feeding azoxymethane (AOM)-induced rats with carrots and purified $\mathrm{FaOH}$ have previously been shown to inhibit neoplastic transformations in the colon. $\mathrm{FaOH}$ and $\mathrm{FaDOH}$ have also shown to have a synergistic effect in vitro, resulting in a significant increased cytotoxic activity. Based on these findings the antineoplastic effect of $\mathrm{FaOH}$ and $\mathrm{FaDOH}$ (purity $>99 \%$ ) was investigated in the AOM-induced rat model. Twenty rats received rat diet containing $7 \mu \mathrm{g} \mathrm{FaOH} \mathrm{per} \mathrm{g}$ feed and $7 \mu \mathrm{g} \mathrm{FaDOH}$ per $\mathrm{g}$ feed and 20 rats were controls receiving only rat diet. Then carcinogenesis was induced in all 40 rats with the carcinogen AOM. All animals received the designated diet for 2 weeks before AOM induction and continued on the designated diet throughout the experiment. Rats were euthanized 18 weeks after the first AOM injection and macroscopic polyp/cancers were measured, harvested and stained for histology. The difference in sizes of aberrant crypt foci (ACF) were analysed in a Wilcoxon rank sum test, in which the median number of small ACF was 218 in controls and 145 in polyacetylene treated rats $(P<0.001)$. Fifteen control rats and 8 treated rats had macroscopic tumors $(P=$ $0.027)$. The number of tumors larger than $3 \mathrm{~mm}$ were 6 and 1 in control and treated rats, respectively $(P=$ 0.032). In conclusion dietary supplements with $\mathrm{FaOH}$ and $\mathrm{FaDOH}$ reduced the number of neoplastic lesions as well as the growth rate of the polyps suggesting a preventive effect of $\mathrm{FaOH}$ and $\mathrm{FaDOH}$ on the development of colorectal cancer.
\end{abstract}

Received 20th January 2017, Accepted 8th February 2017

DOI: 10.1039/c7fo00110j

rsc.li/food-function populations does not reduce the cancer incidence. ${ }^{2,4-10}$ In fact $\beta$-carotene supplementation seems to increase rather than decrease lung cancer incidence in smokers. ${ }^{2,4-7} \beta$-Carotene could, however, be a biomarker for other nutraceuticals with a potential anticancer effect.

Carrots are also a major dietary source of structurally related $\mathrm{C}_{17}$-polyacetylenes of which falcarinol $(\mathrm{FaOH})$, falcarindiol (FaDOH) and falcarindiol 3-acetate (FaDOH3Ac) [Fig. 1] consistently occur in highest concentrations. ${ }^{11-15}$ Among these FaDOH is usually the most abundant followed by $\mathrm{FaOH}^{12,15-18}$ Falcarinol type polyacetylenes have shown many interesting bioactivities including antiinflammatory, ${ }^{13,16,17}$ antiplateletaggregatory, ${ }^{13,17,19-21}$ cytotoxic, ${ }^{11,13,17,22-31}$ and antitumor activity. ${ }^{24,32}$ The antiproliferative effect of $\mathrm{FaOH}, \mathrm{FaDOH}$ and FaDOH3Ac on cancer cells is probably related to their ability to arrest the cell cycle progression at G2/M or other phases of the cell cycles leading to the induction of apoptosis..$^{26,28,30,31,33}$ The exact mechanisms of action of falcarinol type polyacetylenes in cancer cells are, however, not known, but may be related to their alkylating properties as demonstrated recently 

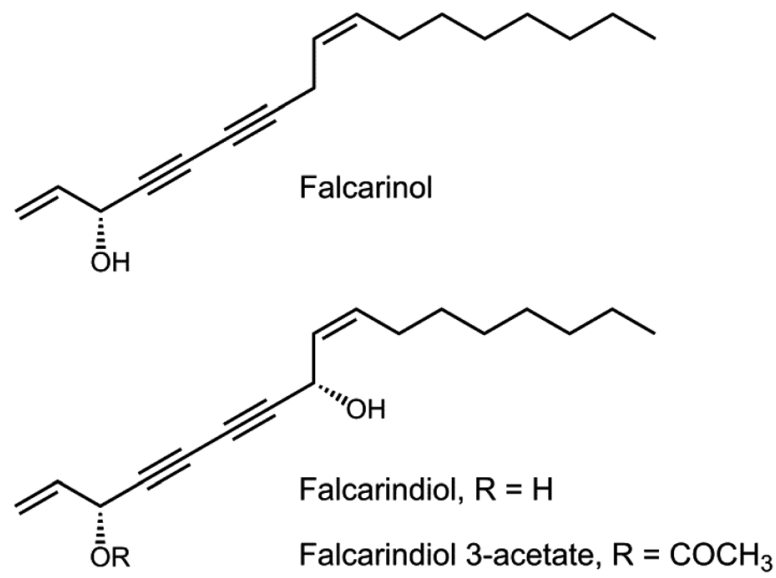

Fig. 1 Chemical structures of $(3 R)$-falcarinol $(\mathrm{FaOH})$, (3R,8S)-falcarindiol $(\mathrm{FaDOH})$ and $(3 R, 8 \mathrm{~S})$-falcarindiol 3 -acetate $(\mathrm{FaDOH} 3 \mathrm{Ac})$, which are the most abundant polyacetylenes in carrots. $\mathrm{FaOH}$ and $\mathrm{FaDOH}$ were isolated from carrots and tested in the AOM-induced rat model in the present investigation.

by Heydenreuter et al. ${ }^{34}$ which showed that $\mathrm{FaOH}$ is able to inhibit enzymes via covalent alkylation. This is also in accordance with $\mathrm{FaOH}$ being a strong contact allergen ${ }^{35}$ and thus may be a potent immune-stimulator. The presence of a secondary alcohol group at C-3 seems to be important for the alkylating properties of $\mathrm{FaOH}$ due to the possibility to generate a reactive resonance stabilized carbocation by the loss of water, which then readily can react with biomolecules involved in, e.g., inflammation and cell proliferation such as the nuclear factor kappa-light-chain-enhancer of activated B cells (NF-kB) signalling pathway, cyclooxygenase (COX)-1 and -2, lipoxygenases (LOXs) and cytokines, ${ }^{13,17,20,29,31}$ and could explain its possible effect on cell cycle arrest. This is in accordance with a study by Purup et al. ${ }^{29}$ which showed that $\mathrm{FaOH}$ significantly inhibited cell proliferation in human epithelial colorectal adenocarcinoma cells (Caco-2) at $2.5 \mu \mathrm{g} \mathrm{mL} \mathrm{m}^{-1}$, whereas its oxidized form, falcarinone [(Z)-1,9-heptadecadiene4,6-diyn-3-one] only inhibited proliferation in Caco-2 cells at $20 \mu \mathrm{g} \mathrm{mL}{ }^{-1}$. In addition $\mathrm{FaOH}$ appears to be more cytotoxic than $\mathrm{FaDOH}^{13,17,24,27,29,31}$ as for example demonstrated by Zidorn et al. ${ }^{27}$ who tested $\mathrm{FaOH}$ and $\mathrm{FaDOH}$ against five different cancer cell lines, including the colorectal carcinoma cell lines HRT-18 and HT-29. The bioactivity of FaDOH3Ac has only been studied in few investigations. In leukemia cell lines it has been demonstrated that FaDOH3Ac was more cytotoxic than $\mathrm{FaOH}$ followed by $\mathrm{FaDOH},{ }^{31}$ whereas in Caco-2 cells FaOH seem to be the most potent of these polyacetylenes. ${ }^{29}$ On the other hand FaDOH is a more potent antiinflammatory agent compared to $\mathrm{FaOH}$ and FaDOH3Ac; ${ }^{16}$ thus the bioactivity of falcarinol type polyacetylenes depends on many factors, although they may have similar mechanisms of action.

The antiproliferative effect of falcarinol type polyacetylenes clearly depends on the cell lines. ${ }^{22,29,31}$ Furthermore, they may work synergistically as demonstrated on the proliferation of Caco-2 cells in vitro for $\mathrm{FaOH}$ and $\mathrm{FaDOH} .{ }^{29}$ By keeping $\mathrm{FaOH}$ constant at $1 \mu \mathrm{g} \mathrm{mL} \mathrm{m}^{-1}$ and incubating Caco-2 cells and normal human intestinal epithelial cells (FHs 74 Int.) with $\mathrm{FaOH}$ and $\mathrm{FaDOH}$ in different ratios, a clear synergistic response on the inhibitory effect of cell proliferation was observed by adding $\mathrm{FaDOH}$ in 1, 5 and 10 times the concentration of $\mathrm{FaOH} .{ }^{29} \mathrm{~A}$ similar synergistic response on the inhibitory effect of cell proliferation was also observed for carrot extracts with different proportions of $\mathrm{FaOH}, \mathrm{FaDOH}$ and $\mathrm{FaDOH} 3 \mathrm{Ac}^{29}{ }^{29}$ The results indicated that $\mathrm{FaDOH}$ in low doses may have very potent inhibitory effects on the proliferation of Caco-2 cells as well as other cell types when found in combination with low doses of $\mathrm{FaOH}$. A similar synergistic effect may be expected for FaDOH3Ac and other falcarinol type polyacetylenes; thus synergistic interactions could be important for their anticancer activity.

Feeding azoxymethane (AOM)-induced rats with carrots and purified $\mathrm{FaOH}$ from carrots have been shown to inhibit neoplastic transformations in the colon. ${ }^{32}$ The potential anticancer activity of carrots and $\mathrm{FaOH}$ was demonstrated by feeding with carrot or purified $\mathrm{FaOH}$ in amounts corresponding to a daily human intake of $400-600 \mathrm{~g}$ fresh weight (FW) of carrot. ${ }^{32}$ Despite of the low concentrations of $\mathrm{FaOH}$ in the rat feed ( $3.5 \mu \mathrm{g} \mathrm{g}^{-1}$ feed) and only 8 rats in each group, dietary treatments with carrots and $\mathrm{FaOH}$, respectively, showed a significant effect $(P=0.028)$ to reduce the number of neoplastic lesions with increasing size of lesion from no difference of the smallest lesions to a one-third reduction for the fully developed tumors. ${ }^{32}$

Colorectal cancer is the third most common type of cancer and accounts for approximately $10 \%$ of all cancer related deaths. ${ }^{36}$ Environmental factors, particularly diet, play roles in the development of this disease. ${ }^{37} \mathrm{FaOH}$ and $\mathrm{FaDOH}$ are not only the most abundant polyacetylenes in carrots but also in many other vegetables of the Apiaceae family, including among others celery, celeriac, and parsnip, in contrast to FaDOH3Ac, which has so far only been detected in carrots; ${ }^{13,17}$ thus $\mathrm{FaOH}$ and $\mathrm{FaDOH}$ are considered to be the most important dietary polyacetylenes. Consequently, the aim of this study was to investigate the inhibitory effect of purified $\mathrm{FaOH}$ and $\mathrm{FaDOH}$ in a combined treatment in AOM-induced rats, in a ratio where these polyacetylenes have shown synergistic inhibitory effect on the proliferation of Caco- 2 cells, and thus to verify earlier observations demonstrating a potential preventive effect of dietary polyacetylenes of the falcarinol type on the development of colorectal cancer.

\section{Materials and methods}

\subsection{Chemicals and reagents}

CHROMASOLV® high-performance liquid chromatography (HPLC) grade of acetonitrile (ACN), ethyl acetate (EtOAc), ethanol (EtOH, 96\%), formic acid, methanol, $n$-hexane and trifluoroacetic acid (TFA) were purchased from Sigma-Aldrich (Steinheim, Germany). Anhydrous sodium sulphate was obtained from Sigma-Aldrich and silica gel 60 aluminium 
sheets for thin-layer chromatography (TLC) and silica gel 60 (particle size $0.063-0.2 \mathrm{~mm}$ ) for column chromatography were purchased from Merck (Darmstadt, Germany). Water was ultrapure generated with a Milli-Q system consisting of an Ultra Clear Basic UV system (Holm \& Halby, Brøndby, Denmark). Azoxymethane (AOM) was purchased from Sigma-Aldrich (A5486) and diluted with sterile $0.9 \% \mathrm{NaCl}$ to a concentration of $5 \mathrm{mg} \mathrm{mL} \mathrm{m}^{-1}$ at the Central Pharmacy of the Odense University Hospital (Odense, Denmark).

\subsection{Isolation and identification of $\mathrm{FaOH}$ and $\mathrm{FaDOH}$}

Carrots (Daucus carota ssp. sativus cv. Miami) were used for extraction of $\mathrm{FaOH}$ and $\mathrm{FaDOH}$. The carrots were obtained from the nursery Vostrup Øko (Vostrup, Tarm, Denmark) and stored in a cold storage room with automatic regulation of the temperature at $5 \pm 0.5{ }^{\circ} \mathrm{C}$ until use. $\mathrm{FaOH}$ and $\mathrm{FaDOH}$ were isolated from carrots according to the procedure described by El-Houri et al. ${ }^{38}$ with a few modifications. Sixty kilograms of shredded carrot roots were extracted twice with $25 \mathrm{~L}$ of EtOAc for $24 \mathrm{~h}$ at $22{ }^{\circ} \mathrm{C}$ in the dark with periodical shaking. The combined extracts were filtered and dried over anhydrous sodium sulphate, and concentrated in vacuo $\left(30^{\circ} \mathrm{C}\right)$ under dim light yielding a combined extract of approximately $84 \mathrm{~g}$. Analysis of the extract by analytical HPLC ${ }^{14,38}$ revealed the presence of FaOH (6.7 $\mathrm{mg} \mathrm{g}^{-1}$ extract) and FaDOH (21.1 $\mathrm{mg} \mathrm{g}^{-1}$ extract) as the main constituents followed by FaDOH3Ac $\left(1.7 \mathrm{mg} \mathrm{g}^{-1}\right.$ extract). The extract was divided into 3 portions of approximately $28 \mathrm{~g}$, and each portion of the extract was chromatographed by flash column chromatography under dim light conditions (400 g, silica gel 60), eluting with $100 \% n$-hexane (600 mL), $n$-hexane-EtOAc (v/v) (9:1, $4: 1,7: 3,3: 2,1: 1,2: 3$, $3: 7,1: 4,1: 9,600 \mathrm{~mL}$ for each step), 100\% ACN (1000 mL), and finally with methanol $(1000 \mathrm{~mL})$. Fractions were analysed by TLC and analytical HPLC ${ }^{14,38}$ and fractions containing crude $\mathrm{FaOH}$ and $\mathrm{FaDOH}$ were combined and further purified by preparative reversed phase (RP)-HPLC on a Dionex UltiMate 3000 Binary Semi-preparative LC System from Thermo Fisher Scientific (Hvidovre, Denmark), equipped with a photodiode array detector (PDA), and a Foxy Jr. fraction collector unit from Teledyne ISCO Inc. (NE, USA). Separations were performed on a Develosil ODS-HG-5 (RP-18, $250 \mathrm{~mm} \times 20 \mathrm{~mm}$ i.d., Nomura Chemical Co., Seto, Japan) column. The mobile phase consisted of water containing $0.05 \%$ TFA (solvent A) and ACN containing $0.05 \%$ TFA (solvent B). The following gradient was used: $25 \% \mathrm{~B}$ at $0 \mathrm{~min} ; 100 \% \mathrm{~B}$ at $55 \mathrm{~min} ; 100 \% \mathrm{~B}$ at $75 \mathrm{~min}$; $25 \% \mathrm{~B}$ at $80 \mathrm{~min} ; 25 \%$ at $90 \mathrm{~min}$. Column temperature was $25{ }^{\circ} \mathrm{C}$, flow rate was $5 \mathrm{~mL} \mathrm{~min}^{-1}$, and injection volume was $2 \mathrm{~mL}$. Compounds were monitored at 210 and $254 \mathrm{~nm}$, and UV spectra recorded between 200 and $600 \mathrm{~nm}$. In total $485 \mathrm{mg}$ of $(3 R)-\mathrm{FaOH}$ and $1245 \mathrm{mg}(3 R, 8 S)-\mathrm{FaDOH}$ was isolated in purity of $>99 \%$ as determined by analytical RP-HPLC and NMR spectroscopy. $\mathrm{FaOH}$ and $\mathrm{FaDOH}$ were obtained as colourless oils and identified by optical rotation, UV-vis, liquid chromatography tandem mass spectrometry (LC-MS/MS), one-dimensional (1D) and 2D NMR $\left({ }^{1} \mathrm{H}\right.$ and ${ }^{13} \mathrm{C}$ NMR and ${ }^{1} \mathrm{H}-{ }^{1} \mathrm{H}$ and ${ }^{1} \mathrm{H}-{ }^{13} \mathrm{C}$ correlation spectroscopy), and the complete spectral data set corresponded fully with literature values. ${ }^{24,32,38-40}$ $\mathrm{FaOH}$ and $\mathrm{FaDOH}$ were stored in $\mathrm{EtOH}$ at $-20{ }^{\circ} \mathrm{C}$ in a concentration of $5 \mathrm{mg} \mathrm{mL} \mathrm{m}^{-1}$ until use. The purified polyacetylene standards are sensitive to heat, light, and oxidation ${ }^{13,17,41}$ and were regularly checked for degradation, oxidation or isomerization by analytical HPLC and NMR (every 3 weeks). No degradation, oxidation or isomerization of the stored polyacetylenes was observed in the animal testing period.

\subsection{Extraction of feed samples}

$1.00 \mathrm{~g}$ of each feed sample was extracted twice with $5 \mathrm{~mL}$ EtOAc for $24 \mathrm{~h}$ at $5{ }^{\circ} \mathrm{C}$ in the dark, mixed frequently and centrifuged at $1000 \mathrm{rpm}$ for $10 \mathrm{~min}$. The supernatant was evaporated to dryness and re-dissolved in $2 \mathrm{~mL}$ EtOAc and filtered by a Q-Max syringe filter $(13 \mathrm{~mm} \varnothing$, PTFE membrane pore size $0.22 \mu \mathrm{m}$, Frisenette APS, Knebel, Denmark) directly into an HPLC vial and analysed by LC-PDA-MS/MS.

\subsection{Analysis of rat diet for $\mathrm{FaOH}$ and $\mathrm{FaDOH}$}

LC-MS analyses were performed on a LTQ XL (Thermo Scientific, Waltham, MA, USA) equipped with an Accela HPLC pump and PDA detector. The HPLC separations were carried out on a Luna C18-2 column $(150 \times 4.6 \mathrm{~mm}, 3 \mu \mathrm{m}, 100 \AA$, Phenomenex, Allerød, Denmark) at room temperature. The mobile phase consisted of solvent A (aqueous $0.1 \%$ formic acid) and solvent B (ACN with $0.1 \%$ formic acid) and the following gradient system was used: 10-99\% B (40 $\mathrm{min}$ ), 99\% B (34 min), 99-10\% B (1 min), 10\% B (5 min). Flow rate was $0.4 \mathrm{~mL} \min ^{-1}$ and the injection volume $10 \mu \mathrm{L}$. The MS was run with the atmospheric pressure chemical ionization (APCI) in positive mode and with single ion monitoring (SIM). Settings for the mass spectrometer were 50, 5 and 5 (arbitrary units) for sheath, auxiliary and sweep gas flow rates, respectively, vaporizer temperature $450{ }^{\circ} \mathrm{C}$, discharge current $5 \mu \mathrm{A}$, capillary temperature $275^{\circ} \mathrm{C}$, capillary voltage $19 \mathrm{~V}$, tube lens $40 \mathrm{~V}$. Ions with $\mathrm{m} / \mathrm{z} 225$ and 243 were used for SIM recording with 2 units $\mathrm{m} / \mathrm{z}$ width. The LC-MS/MS method was validated with regard to linearity, precision and reproducibility in the range of quantification. Quantification of $\mathrm{FaOH}$ and $\mathrm{FaDOH}$ in the rat diets was based on a calibration curve in the range of $1-15 \mu \mathrm{g} \mathrm{mL} L^{-1}$ for both $\mathrm{FaOH}$ and $\mathrm{FaDOH}\left(R^{2}>0.998\right.$ for both polyacetylenes $)$.

\subsection{Animals}

All animal experiments were approved by the Central Animal Experimentation Inspectorate in Denmark (License no. 201515-0201-00708). Male rats from the F344 strain with a certified health report were purchased from Charles River. The animals were 5 weeks old at the time of arrival. After one week of acclimatization, the rats were divided into 2 groups and started on the dedicated diets. The rats were feed on the different diets for 2 weeks before the first injection with AOM at the age of 8 weeks, as described in earlier studies. ${ }^{32}$ All animals were housed in groups of two rats in Macrolon type III cages during the study (Scanbur A/S Køge, Denmark). The rats were treated with AOM in a fume hood and AOM treated rats were housed in a ventilated cabinet with negative pressure 
(3 mm water). Two weeks after the final AOM injection, the animals were moved outside the ventilated cabinet and housed in a conventional animal room. Rats that did not receive AOM injections were housed outside the conventional animal room throughout the experiment. The animals were kept under standard laboratory conditions: room temperature, 20-24 ${ }^{\circ} \mathrm{C}$; relative humidity, 50-60\%; and $12 \mathrm{~h}$ light/dark cycles (lights on from 6 a.m. to 18 p.m.). Inside the ventilated cabinet, the bedding consisted of ALPHA-dri ${ }^{\circledR}$ made from alpha-cellulose and nest material was Enviro-dri®, and the cages were changed twice a week. While outside the ventilated cabinet under conventional housing, the rats were given nesting material Enviro-dri ${ }^{\circledR}$ and Aspen wood bedding (Tapvei) twice a week. Animals in the ventilated cabinet were allowed free access to acidified tap water (acidified with $\mathrm{HCl}$ to pH 4) via water bottles. Food was available ad libitum throughout the experiment. Fresh food was given at least once a week.

\subsection{Rat diet}

Powder/meal maintenance rat diet (Altromin 1321, Brogaarden Denmark) was used as standard diet for feeding the rats. Diet group 1 contained standard rat feed supplemented with $7 \mu \mathrm{g}$ $\mathrm{FaOH}$ per $\mathrm{g}$ feed and $7 \mu \mathrm{g} \mathrm{FaDOH}$ per $\mathrm{g}$ feed; diet group 2 had only standard rat feed. Because the purified $\mathrm{FaOH} / \mathrm{FaDOH}$ was added to the diet in the form of an EtOH solution, the diet of the control group (group 2) was also treated with the same amount of EtOH. Weekly, portions of $3.5 \mathrm{~kg}$ diet were prepared for each of the two groups. In this preparation either $100 \mathrm{~mL}$ of $96 \%$ EtOH containing $50 \mathrm{mg}$ of $\mathrm{FaOH}$ and $\mathrm{FaDOH}$ in a $1: 1$ ratio or $100 \mathrm{~mL}$ of $96 \% \mathrm{EtOH}$ (vehicle) was applied to the diets using an atomizer, after which the portion was allowed to dry at room temperature for approximately $1 \mathrm{~h}$ in darkness before being packed in dark plastic backs and placed in a plastic box. The prepared diets were stored at room temperature, mixed well before use, and used for approximately 1 week before new diets were prepared. The content of $\mathrm{FaOH}$ and $\mathrm{FaDOH}$ in the rat diets (groups 1 and 2) was measured by LC-MS/MS before use and samples from each diet preparation were analysed throughout the experiment (Table 1) with the diet from group 2 used as a negative control, which showed no presence of polyacetylenes (data not shown). No sign of degradation, oxidation or isomerization of $\mathrm{FaOH}$ and $\mathrm{FaDOH}$ was observed during the experiment as well as no significant differences in the content of $\mathrm{FaOH}$ or $\mathrm{FaDOH}$ in the weekly prepared diet.

\subsection{Design of the rat feeding experiments}

A total of 48 rats were divided into two groups that received different diets, starting 14 days before the first AOM injection. The AOM solution was stored for about $1 \mathrm{~h}$ at room temperature before being injected. Twenty of the 24 animals in each treatment group were given weekly subcutaneous injections of freshly prepared AOM at a dose of $15 \mathrm{mg}$ per $\mathrm{kg}$ body weight for a period of $2 \times 2$ weeks separated by a 1 week break. The injection volume used was $0.4 \mathrm{~mL}$ at the start and $1.0 \mathrm{~mL}$ at the end of the AOM treatments. Four control rats in each treat-
Table 1 Concentration of falcarinol $(\mathrm{FaOH})$ and falcarindiol ( $\mathrm{FaDOH})$ in the rat feed of the active arm prepared in the different weeks of the preclinical trial. The concentration of $\mathrm{FaOH}$ and $\mathrm{FaDOH}\left(\mu \mathrm{g} \mathrm{g}^{-1}\right.$ feed) was determined by LC-MS/MS in triplicates and values are given as mean values \pm standard deviation

\begin{tabular}{lll}
\hline Week number & FaOH $\left(\mu \mathrm{g} \mathrm{g}^{-1}\right.$ feed $)$ & FaDOH $\left(\mu \mathrm{g} \mathrm{g}^{-1}\right.$ feed $)$ \\
\hline 1 & $6.63 \pm 0.63$ & $7.27 \pm 1.26$ \\
2 & $6.94 \pm 1.21$ & $6.66 \pm 1.22$ \\
3 & $6.40 \pm 1.07$ & $7.46 \pm 0.10$ \\
4 & $6.51 \pm 0.22$ & $6.38 \pm 0.44$ \\
$5-6$ & $6.53 \pm 0.71$ & $6.43 \pm 0.66$ \\
$7-8$ & $6.40 \pm 0.93$ & $7.25 \pm 0.84$ \\
$9-11$ & $7.03 \pm 1.30$ & $6.75 \pm 1.08$ \\
12 & $7.18 \pm 0.31$ & $7.03 \pm 0.40$ \\
13 & $6.20 \pm 0.68$ & $6.71 \pm 0.89$ \\
14 & $6.82 \pm 0.56$ & $7.09 \pm 0.51$ \\
15 & $6.75 \pm 1.35$ & $6.44 \pm 1.42$ \\
$16-18$ & $6.90 \pm 0.71$ & $6.72 \pm 0.66$ \\
19 & $6.75 \pm 0.31$ & $7.30 \pm 0.40$ \\
Total mean concentration & $6.88 \pm 0.76$ & $6.70 \pm 0.77$
\end{tabular}

ment group were injected with a volume of sterile $0.9 \% \mathrm{NaCl}$ related to the body weight.

\subsection{Autopsy procedures}

The rats were euthanized after 18 weeks and autopsied to examine for macroscopic alterations. The animals were killed by cervical dislocation, after they had been anaesthetized with isoflurane inhalation. Immediately after death, selected organs were fixed in $4 \%$ phosphate-buffered formaldehyde, $\mathrm{pH} 7.4$, for later histopathological examination. The total length of the intestine was measured, and it was then cut longitudinally, rinsed in $0.9 \% \mathrm{NaCl}$ solution, and pinned on a plastic slab. Before fixation, the large intestine was evaluated for macroscopic neoplasms, where diameter and location in the intestine were registered.

\subsection{Identification and quantification of tumours and aberrant crypt foci (ACF)}

After fixation of the large intestine, Giemsa stain $[6 \mathrm{~mL}$ of stock solution (The Central Pharmacy at the Odense University Hospital) in $50 \mathrm{~mL}$ of phosphate-buffered saline (PBS), pH 7.2, for $15 \mathrm{~min}$ ] was used to visualize the ACF, and excess stain was rinsed off with PBS. The tissue was placed with the luminal side up in a Petri dish with enough PBS to cover the tissue. The total numbers of ACF and tumours for each section were counted independently by two persons, blinded to treatment modality, by using a stereomicroscope at $40 \times$ magnification. The aberrant crypts were distinguished by their increased size and thicker and deeply stained epithelial lining as compared with normal crypts (Fig. 2). An ACF may consist of one to several crypts, and in the present study, the ACF were classified as small (1-7 crypts) or large (more than seven crypts), while neoplasms $1-3 \mathrm{~mm}$ in diameter were classified as minor tumours. Tumours more than $3 \mathrm{~mm}$ in diameters were classified as large tumours. Within each class of lesions, the variation coefficient of the two counts was less than $10 \%$. The two counts were averaged. 

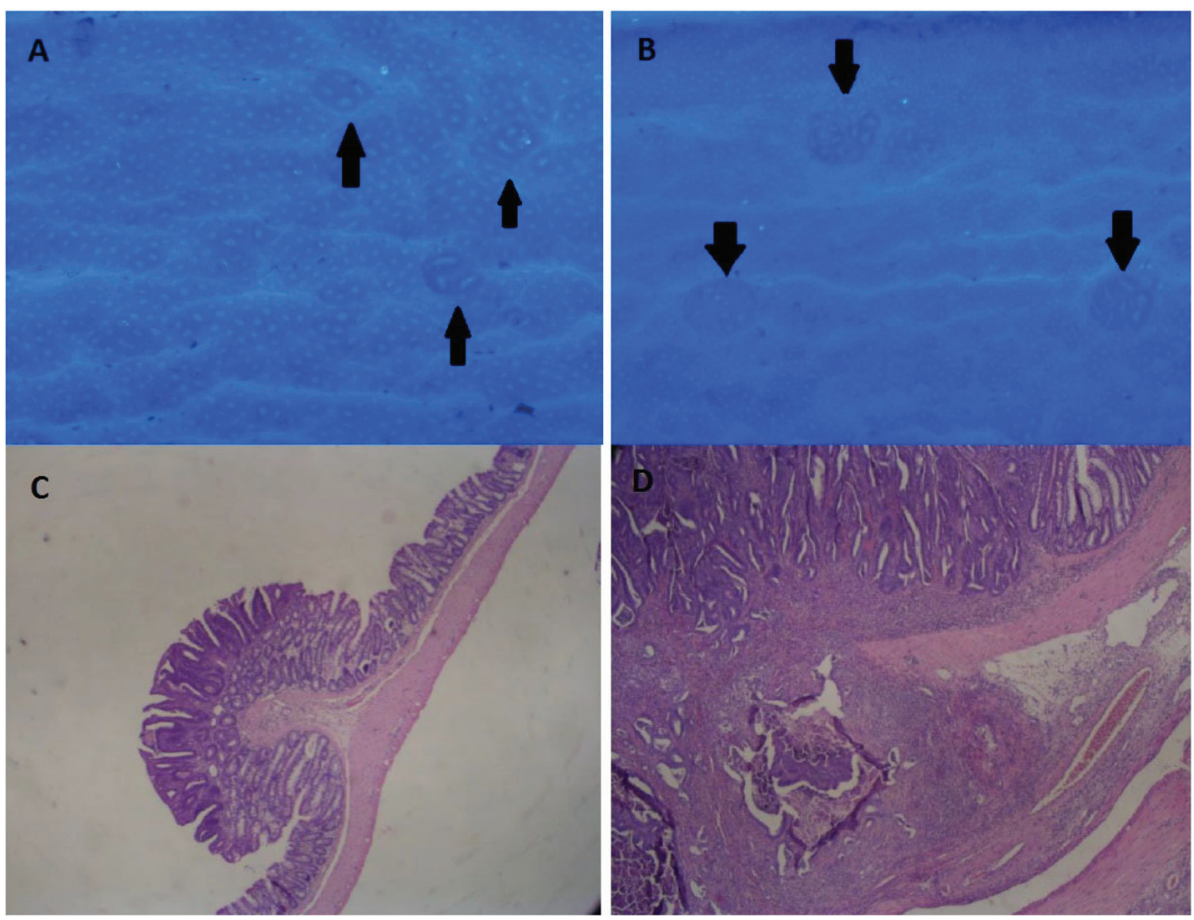

Fig. 2 Aberrant crypts foci (ACF) were distinguished by their increased size and thicker and deeply stained epithelial lining as compared with normal crypts. Histology was verified by hematoxylin and eosin staining. Appearance of small ACF (arrows) (A); appearance of large ACF (arrows) (B); histology of adenoma (C), and histology of carcinoma (D).

Macroscopic findings were fixed in $4 \%(\mathrm{v} / \mathrm{v})$ formaldehyde buffered with $0.075 \mathrm{M}$ sodium phosphate $(\mathrm{pH} 7)$ and embedded in paraffin. The tissues from tumours $>3 \mathrm{~mm}$ were cut into $5 \mu \mathrm{m}$ sections and were stained with hematoxylin and eosin. Additional sections were cut until characterization of the neoplasm was certain. The sum of lesions from large ACF and small macroscopic tumours were used in the calculation of the percentage reduction, because of the two categories were overlapping findings.

\subsection{Statistical analysis}

The occurrence of macroscopic tumours, and tumours larger than $3 \mathrm{~mm}$, was tested between control and treated rats using a chi-square test. Data were analysed using exact methods for binomial data. A chi-squared test was used to assess the hypothesis of no difference in risk. Estimates are given with $95 \%$ confidence intervals. The number of ACF was tested between the groups using Wilcoxon rank sum test, data were analysed as two independent samples from the same distributions based on the Wilcoxon-signed rank. The assumption of equal distribution was checked by means and variances. Estimates are given with $95 \%$ confidence intervals.

\section{Results}

$\mathrm{FaOH}$ and $\mathrm{FaDOH}$ were isolated from organic grown carrots of the cultivar Miami by flash column chromatography and preparative HPLC. The purified polyacetylenes (purity > 99\%) were identified as $(3 R)-\mathrm{FaOH}$ and $(3 R, 8 S)$-FaDOH (Fig. 1) by spectrometric and spectroscopic techniques (see Materials and methods). Falcarinol type polyacetylenes like most polyacetylenes are thermally unstable and furthermore may undergo photodecomposition if exposed to UV light as well as oxidative and pH-dependent decomposition. ${ }^{13,17,41}$ However, regularly control of the purified polyacetylene standards stored in EtOH at $-20^{\circ} \mathrm{C}$ by analytical RP-HPLC and NMR did not show any sign of degradation, oxidation or isomerization of these compounds in the testing period of 19 weeks. The contents of $\mathrm{FaOH}$ and $\mathrm{FaDOH}$ were determined in all batches of feed of the active arm by LC-MS/MS, although a few batches from week 5-6, 7-8, 9-11 and 16-18 were combined, respectively, and analysed as one batch in triplicate (Table 1). The control rat diet contained no polyacetylenes (data not shown) and the mean contents of $\mathrm{FaOH}$ and $\mathrm{FaDOH}$ in the feed of the active arm were $6.88 \pm 0.76 \mu \mathrm{g} \mathrm{g}^{-1}$ feed and $6.70 \pm 0.77 \mu \mathrm{g} \mathrm{g} \mathrm{g}^{-1}$ feed, respectively (Table 1). Furthermore, analyses of random samplings from batches of feed of the active arm during the feeding experiments showed no sign of degradation, oxidation or isomerization of $\mathrm{FaOH}$ and $\mathrm{FaDOH}$ in accordance with the fact that no significant changes in the content of these polyacetylenes were observed (data not shown). It can therefore be concluded that the feed of the active arm contained the prescribed amount of $\mathrm{FaOH}$ and $\mathrm{FaDOH}$ of $7 \mu \mathrm{g} \mathrm{FaOH}$ per $\mathrm{g}$ feed and $7 \mu \mathrm{g}$ FaDOH per $\mathrm{g}$ feed during the whole trial.

Fifteen out of twenty control rats and eight out of twenty $\mathrm{FaOH} / \mathrm{FaDOH}$ treated rats had macroscopic tumours $(P=$ 0.027) [Fig. 3]. No drop outs due to death or disease occurred 

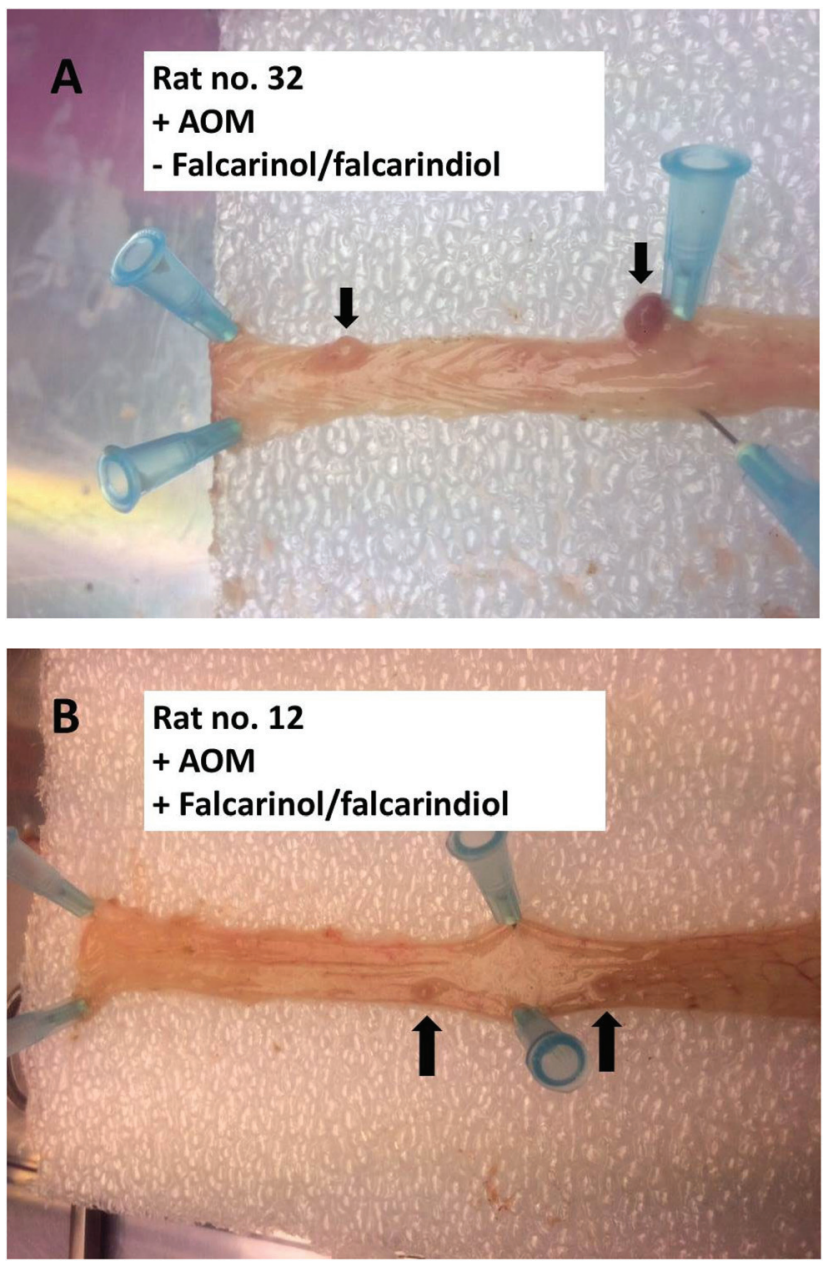

Fig. 3 Macroscopic appearance of tumours. A, Rat that received control diet without polyacetylenes and with macroscopic appearance of 2 tumours (arrows) of 3-4 mm in diameter. B, Rat that received a diet containing $\mathrm{FaOH}$ and $\mathrm{FaDOH}$ and with macroscopic appearance of 2 tumours (arrows) of approximately $1 \mathrm{~mm}$ in diameter.

before they were euthanized. All results are summarized in Table 2. The median number of small ACF was 218 in control and 145 in treated rats $(P<0.001)$. The total numbers of neoplasia identified under macroscopic examination of the rat intestine were 21 tumours in the group of control rats and 12 in the $\mathrm{FaOH} / \mathrm{FaDOH}$ treated rats. Number of tumours larger

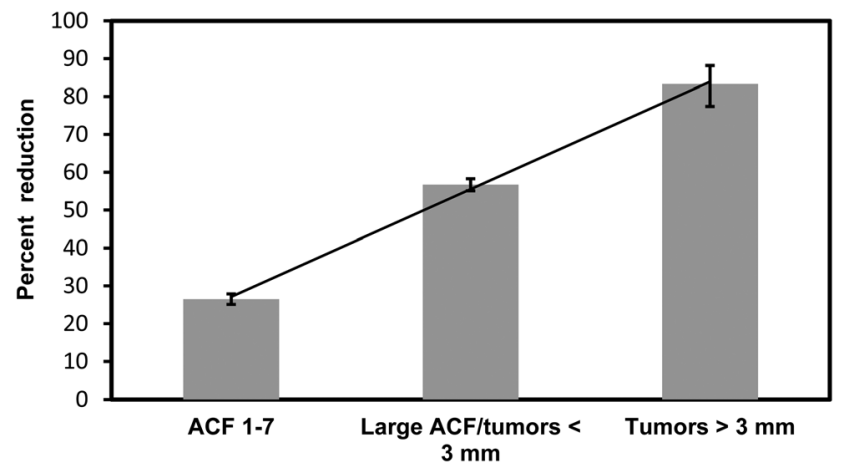

Fig. 4 Percent reduction of lesions in $\mathrm{FaOH}$ and $\mathrm{FaDOH}$ treated animals compared to control group. The reduction in the size of lesions was linear correlated $\left(R^{2}>0.9987\right)$.

than $3 \mathrm{~mm}$ were 6 in the group of control rats and 1 in the $\mathrm{FaOH} / \mathrm{FaDOH}$ treated rats $(P=0.032)$. Tumours larger than $3 \mathrm{~mm}$ were confirmed as neoplastic by histological analyses. No adenocarcinomas developed in the observation period.

The number of lesions in the group of rats receiving feed containing $\mathrm{FaOH}$ and $\mathrm{FaDOH}$ compared to the rats receiving control feed, showed a linear correlation to size (Fig. 4). The reduction in percentage for small ACF was 33.6\%, and for large ACF and small macroscopic tumours it was $56.7 \%$ and for tumours larger than $3 \mathrm{~mm}$ it was $83.3 \%$. In addition, 11 neoplasms were found in the small bowel of rats receiving feed containing $\mathrm{FaOH}$ and $\mathrm{FaDOH}$ and 17 neoplasms in the rats receiving control feed.

\section{Discussion}

Colorectal cancer results from changes in cell transformation of colonic epithelial tissue with the initial development of dysplastic crypts, adenomatous polyps and then cancer. ${ }^{42-44} \mathrm{AOM}$ is a potent carcinogen that has been shown to be an efficient inducer of colorectal cancer in rats, ${ }^{42,43}$ and it has been shown that the AOM-induced rat model represents a good predictor of chemopreventive efficacy in humans. ${ }^{45}$

In the early stages of colorectal carcinogenesis, dysplasia in the intestinal mucosa occurs with variable degrees of complexity, called aberrant crypt foci (ACF). ${ }^{42}$ In the AOM-induced

Table 2 Total numbers of neoplastic lesions in rats receiving diet containing $\mathrm{FaOH}$ and $\mathrm{FaDOH}$ compared to rats receiving control diet

\begin{tabular}{|c|c|c|c|c|}
\hline & $\begin{array}{l}\text { Number of small } \\
\text { (1-7) ACF clusters }\end{array}$ & $\begin{array}{l}\text { Number of large } \\
(>7) \text { ACF clusters }\end{array}$ & $\begin{array}{l}\text { Minor tumors } \\
1-3 \mathrm{~mm}\end{array}$ & $\begin{array}{l}\text { Number of } \\
\text { tumors }>3 \mathrm{~mm}\end{array}$ \\
\hline Rats receiving control diet $(n=20)$ & $\begin{array}{l}4094 \\
\text { Median = } 218\end{array}$ & 126 & 15 & 6 \\
\hline Rats receiving diet containing $\mathrm{FaOH} / \mathrm{FaDOH}(n=20)$ & $\begin{array}{l}3007 \\
\text { Median = } 145\end{array}$ & 50 & 11 & 1 \\
\hline Percent reduction $^{a}$ & $26.6(P<0.001)$ & $56.7(P=0.027)$ & & $83.3(P=0.032)$ \\
\hline
\end{tabular}

${ }^{a}$ Percent reduction of lesions in each category is indicated with the significance level in parenthesis. Large ACF and small macroscopic tumours were overlapping findings; thus their sum was used in the calculation of the percentage reduction of these categories of neoplastic lesions. 
rat model ACF are considered as putative preneoplastic lesions in the colon epithelium and ACF can be used as biomarkers to assess the efficacy of potential chemopreventive agents. ${ }^{46}$ Some of these lesions are precursors of adenomatous polyps and colorectal adenomas in rats and humans. ${ }^{47}$ However, only a proportion of the neoplastic lesions will develop into adenocarcinomas. The proportion of ACF that develop into macroscopic adenomas and further into cancer is unknown, but the pathway is generally accepted. The small ACF was significantly reduced by approximately $34 \%$ in the $\mathrm{FaOH} / \mathrm{FaDOH}$ group compared to controls and for the large ACF ( $>7)$ a reduction of approximately $57 \%$ was observed, this reduction was also significant (Table 2). However, as large ACF and small macroscopic tumours were overlapping findings their sum were used in the calculation of the percentage reduction of these categories of neoplastic lesions (Table 2). In the group treated with $\mathrm{FaOH} / \mathrm{FaDOH}$ the number of tumours larger than $3 \mathrm{~mm}$ was reduced by approximately $83 \%$ compared to the control group, and this difference was also significant (Table 2). Thus, it can be concluded that $\mathrm{FaOH}$ and $\mathrm{FaDOH}$ are able to inhibit neoplastic development in the colon. The effects observed in this study are, however, much more significant compared to those of our previous study, ${ }^{32}$ where an effect of carrots and $\mathrm{FaOH}$ (purity > 98\%) treatments, respectively, was only observed on the development of tumours and large ACF, whereas no effect was observed on small ACF. In the present study the rat diet in the test group was supplemented with $\mathrm{FaOH}$ and $\mathrm{FaDOH}$ (purity $>99 \%$ ) to the final concentration of $7 \mu \mathrm{g} \mathrm{FaOH}$ per $\mathrm{g}$ feed and $7 \mu \mathrm{g}$ FaDOH per $\mathrm{g}$ feed thereby taken into account possible synergistic action of their antiproliferative activity. ${ }^{29}$ Furthermore, the concentrations of $\mathrm{FaOH}$ and $\mathrm{FaDOH}$ in this study are in total approximately 4 -fold higher compared to the $\mathrm{FaOH}$ concentration used in our previous study. Altogether this may explain the significant inhibitory effect observed on all sizes of neoplastic lesions in the colon in the present study.

The intake of feed per day for a $200 \mathrm{~g}$ rat is approximately 20 g. Consequently, each rat in the test group ate approximately $0.14 \mathrm{mg} \mathrm{FaOH}$ and $0.14 \mathrm{mg}$ FaDOH per day corresponding to $0.7 \mathrm{mg} \mathrm{FaOH}$ per $\mathrm{kg}$ and $0.7 \mathrm{mg}$ FaDOH per $\mathrm{kg}$ rat per day. Due to the faster metabolic rate of rats compared to humans, metabolic calculations must be taken into account if one attempt to calculate equivalent doses to humans. A $70 \mathrm{~kg}$ person should therefore eat about $12 \mathrm{mg} \mathrm{FaOH}$ and $12 \mathrm{mg}$ FaDOH daily to achieve a similar exposure if one assume that these polyacetylenes are readily available and are released in the colon. $\mathrm{FaOH}$ and FaDOH have been shown to be bioavailable and detectable in the systemic circulation in humans after oral intake of carrots, ${ }^{13,17}$ in accordance with their lipophilicity; hence, when released in the colon falcarinol type polyacetylenes possesses the ability to enter epithelial cells in the colon, although this requires further investigations.

The distribution of the most abundant polyacetylenes in carrots is known to vary among different genotypes. The content of these polyacetylenes in cultivated carrot cultivars varies from 8-424 mg per $\mathrm{kg}$ FW for FaDOH, 0.8-281 mg per kg FW for FaOH and 1-149 mg per kg FW for FaDOH3Ac. ${ }^{12,15}$ In addition the ratio between $\mathrm{FaOH}, \mathrm{FaDOH}$ and $\mathrm{FaDOH} 3 \mathrm{Ac}$ varies also with $\mathrm{FaDOH}$ often being the most abundant and FaDOH3Ac occurring in lowest concentration. The concentration of these polyacetylenes in the carrot cultivar $D$. carota ssp. sativus cv. Miami used for the isolation of $\mathrm{FaOH}$ and FaDOH was determined by analytical HPLC-PDA ${ }^{14}$ to be: $10.3 \mathrm{mg} \pm 0.9 \mathrm{mg} \mathrm{FaOH}$ per $\mathrm{kg}$ FW, $32.6 \mathrm{mg} \pm 3.1 \mathrm{mg}$ FaDOH per $\mathrm{kg}$ FW and $3.6 \mathrm{mg} \pm 1.2 \mathrm{mg}$ FaDOH3Ac per $\mathrm{kg} \mathrm{FW}$, and is in accordance with the concentrations and ratio of these polyacetylenes previously found in organic Danish grown carrot cultivars. ${ }^{12}$ Compared to cultured forms of carrots, the levels of $\mathrm{FaOH}$ and $\mathrm{FaDOH}$ in some D. carota wild relatives can be up to 10-20 times higher, whereas the differences in the content of FaDOH3Ac is less pronounced..$^{15}$ The cultivated carrot cultivar 'Nantes Empire' has been reported to contain $46 \mathrm{mg} \mathrm{FaOH}$ per $\mathrm{kg}$ FW and $235 \mathrm{mg}$ FaDOH per $\mathrm{kg} F W,{ }^{15}$ which means that a person of $70 \mathrm{~kg}$ should eat around $260 \mathrm{~g}$ of this cultivar to obtain the effective dose of both polyacetylenes, if we assume that all the content of polyacetylenes in the fresh carrots is released in the colon. However, the wild relative D. carota ssp. carota has been reported to contain $1073 \mathrm{mg}$ FaOH per $\mathrm{kg}$ FW and $1003 \mathrm{mg}$ FaDOH per $\mathrm{kg}$ FW..$^{15}$ This means that a person of $70 \mathrm{~kg}$ should only eat $12 \mathrm{~g}$ carrots per day to obtain the same exposure of $\mathrm{FaOH}$ and $\mathrm{FaDOH}$ as in the present preclinical trial. Consequently, it is realistic to assume that the amounts of $\mathrm{FaOH}$ and $\mathrm{FaDOH}$ used for testing in this preclinical trial can be achieved by a daily intake of for example fresh carrots or in the form of fresh carrot juice or smoothies. FaDOH3Ac may also contribute to the anticancer effect of carrots. However, as this polyacetylene has only been detected in carrots and usually occur in much lower concentrations compared to $\mathrm{FaOH}$ and $\mathrm{FaDOH}$, as also demonstrated in the present investigation, its contribution to the health promoting effects of vegetables containing falcarinol type polyacetylenes is considered to be relatively limited. FaDOH3Ac was therefore not attempted isolated and included in this preclinical trial.

After subcutaneous injection of AOM in the rat, it is entering the circulation and the carcinogen is metabolized in the liver and then excreted to the intestinal system, resulting in macroscopic tumours of the colon and rectum, which was observed in 15 control rats out of 20 receiving AOM in the present study. The high incidence of small bowel tumours observed in the duodenum indicates that the carcinogens are excreted to the intestinal system via the bile system. Due to the fact that rats do not have a gall bladder, the highly reactive metabolites are excreted together with the bile directly into the duodenum of the rat; hence, the excretion of the carcinogens is not coordinated with feed intake. The carcinogens are mixed with the feed in the duodenum, and transported to the large intestine where they induce neoplasms in the colon of the rats. The mechanism by which the polyacetylenes prevent the neoplastic development is unknown; however, parts of the mechanism might be connected with direct interaction between $\mathrm{FaOH}$ and $\mathrm{FaDOH}$ and the carcinogen or metabolites from the carcinogen, thus preventing hypermethylation of the 
intestinal cells. The reduction in growth rate of the neoplastic lesions observed in the present study is, however, executed later, when AOM is no longer present in the rats, and therefore the observed inhibitory effect on the formation of neoplastic lesions of $\mathrm{FaOH}$ and $\mathrm{FaDOH}$ must be due to different modes of action. It has previously been shown that inhibition of COX-2 reduces the incidence of preneoplastic cells in rats treated with AOM. ${ }^{48,49} \mathrm{FaDOH}$ has shown to be an effective inhibitor of COX-1 and COX-2, whereas the COX inhibitory activity of $\mathrm{FaOH}$ is less pronounced. ${ }^{17,21,33,50,51}$ In addition $\mathrm{FaOH}$ and $\mathrm{FaDOH}$ have shown to inhibit the formation of the pleiotropic proinflammatory cytokines interleukin-6 (IL-6), IL-1 $\beta$ and tumour necrosis factor (TNF)- $\alpha,{ }^{16}$ and thus the activation of their upstream NF- $\kappa \mathrm{B}$, signalling pathway, which is crucial for neoplastic transformation and promotion. ${ }^{52}$ Accordingly $\mathrm{FaOH}$ and $\mathrm{FaDOH}$ are also strong inhibitors of LOXs, including 5-, 12- and 15-LOX, ${ }^{17,20}$ that are also involved in tumour-progression and activation of NF- $\kappa \mathrm{B}$. Although the COX inhibitory activity of $\mathrm{FaDOH}$ and $\mathrm{FaOH}$ might add to the explanation of the observed antineoplastic effect in this investigation, it may not be the only explanation as mentioned above and in the introduction; hence the mechanisms of action of the preventive effect of $\mathrm{FaOH}$ and $\mathrm{FaDOH}$ on colorectal cancer requires further investigations. It is, however, encouraging that the dose used in the present investigation of these polyacetylenes is within the range of normal daily intake of carrots, which does not cause any toxic effects in humans. $\mathrm{FaOH}$ has so far only shown unwanted toxic effects when delivered in high doses upon injection $\left(100 \mathrm{mg} \mathrm{kg}^{-1}\right)$ to rodents, where it causes neurotoxic symptoms, ${ }^{53}$ whereas FaDOH does not seem to have any toxic effect. ${ }^{54}$ Unwanted toxic effects of $\mathrm{FaOH}$ and $\mathrm{FaDOH}$ in humans by even a relatively high intake of carrots and/or processed carrot products or other Apiaceae vegetables is therefore not expected.

\section{Conclusions}

The present study has demonstrated that dietary supplements of $\mathrm{FaOH}$ and $\mathrm{FaDOH}$ reduced the number of neoplastic lesions formed as well as the growth rate of the polyps suggesting a preventive effect of these polyacetylenes on the development of colorectal cancer in AOM-induced rats. Furthermore, the amounts of polyacetylenes used in the preclinical trial can be achieved by a daily normal intake of carrots. Moreover it is not unlikely to assume that a normal intake of cultivated carrot cultivars containing high concentrations of $\mathrm{FaOH}$ and $\mathrm{FaDOH}$ will expose the colon for relative higher concentrations of polyacetylenes than in the present preclinical trial. Thus it could be interesting to determine the concentration of $\mathrm{FaOH}$ and FaDOH where an optimal preventive effect on neoplastic lesions in the colon is achieved in a $\mathrm{FaOH} / \mathrm{FaDOH}$ doseresponse preclinical trial. Eventually, such a study could be important for the preparation of clinical trials investigating the preventive effect of carrots and/or processed carrot products on the formation of neoplastic lesions and on the devel- opment of colorectal cancer in humans. It will also be obvious to investigate the possible mechanisms of action of falcarinol type polyacetylenes in preclinical and clinical trials, and in particular $\mathrm{FaOH}$ and $\mathrm{FaDOH}$ as they appear to be the most important dietary polyacetylenes based on the present and previous studies.

\section{Abbreviations}

$\begin{array}{ll}\text { ACF } & \text { Aberrant crypt foci } \\ \text { ACN } & \text { Acetonitrile } \\ \text { AOM } & \text { Azoxymethane } \\ \text { Caco-2 } & \text { Human epithelial colorectal adenocarcinoma cells } \\ \text { COX } & \text { Cyclooxygenase } \\ \text { EtOAc } & \text { Ethyl acetate } \\ \text { EtOH } & \text { Ethanol } \\ \text { FaOH } & \text { Falcarinol } \\ \text { FaDOH } & \text { Falcarindiol } \\ \text { FaDOH3Ac } & \text { Falcarindiol 3-acetate } \\ \text { FW } & \text { Fresh weight } \\ \text { IL } & \text { Interleukin } \\ \text { LOX } & \text { Lipoxygenase } \\ \text { NF- } \kappa \text { B } & \text { Nuclear factor kappa-light-chain-enhancer of acti- } \\ & \text { vated B cells } \\ \text { PBS } & \text { Phosphate-buffered saline } \\ \text { TFA } & \text { Trifluoroacetic acid }\end{array}$

\section{Conflict of interest}

The authors declare no conflict of interest.

\section{Acknowledgements}

We thank Dr Kai Grevsen Department of Food Science, Aarhus University, Denmark and the nursery Vostrup Øko, Denmark for the carrots. We also thank Department of Pathology at Odense University Hospital for technical support during evaluation of the study. Finally, we thank Biomedical Laboratory at University of Southern Denmark for technical support of the animal experiments.

\section{Notes and references}

1 M. E. O'Neill, Y. Carroll, B. Corridan, B. Olmedilla, F. Granado, I. Blanco, H. Van den Berg, I. Hininger, A. M. Rousell, M. Chopra, S. Southon and D. I. Thurnham, A European carotenoid database to assess carotenoid intakes and its use in a five country comparative study, Br. J. Nutr., 2001, 85, 499-507.

2 The Alpha-Tocopherol, Beta-Carotene Cancer Prevention Study Group, The effect of vitamin $\mathrm{E}$ and $\beta$-carotene on the incidence of lung cancer and other cancers in male smokers, N. Engl. J. Med., 1994, 330, 1029-1035. 
3 P. Astorg, Food carotenoids and cancer prevention: an overview of current research, Trends Food Sci. Technol., 1997, 8, 406-413.

4 G. S. Omenn, G. E. Goodmann, M. D. Thornquist, J. Balmes, M. R. Cullen, A. Glass, J. P. Keogh, F. L. Meyskens, B. Valanis, J. H. Williams, S. Barnhart and S. Hammar, Effects of a combination of $\beta$-carotene and vitamin A on lung cancer and cardiovascular disease, N. Engl. J. Med., 1996, 334, 1150-1155.

5 E. R. Greenberg, J. A. Baron, M. R. Karagas, T. A. Stukel, D. W. Nierenberg, M. M. Stevens, J. S. Mandel and R. W. Haile, Mortality associated with low plasma concentration of $\beta$-carotene and the effect of oral supplementation, J. Am. Med. Assoc., 1996, 275, 699-703.

6 D. Albanes, O. P. Heinonen, P. R. Taylor, J. Virtamo, B. K. Edwards, M. Rautalahti, A. M. Hartman, J. Palmgren, L. S. Freedman, J. Haapakoski, M. J. Barrett, P. Pietinen, N. Malila, E. Tala, K. Liippo, E. R. Salomaa, J. A. Tangrea, L. Teppo, F. B. Askin, E. Taskinen, Y. Erozan, P. Greenwald and J. K. Huttunen, $\alpha$-tocopherol and $\beta$-carotene supplements and lung cancer incidence in the AlphaTocopherol, Beta-Carotene Cancer Prevention Study: Effects of base-line characteristics and study compliance, J. Natl. Cancer Inst., 1996, 88, 1560-1570.

7 R. G. Ziegler, E. A. Colavito, P. Hartge, M. J. McAdams, J. B. Schoenberg, T. J. Mason and J. F. Fraumeni Jr., Importance of $\alpha$-carotene, $\beta$-carotene, and other phytochemicals in the etiology of lung cancer, J. Natl. Cancer Inst., 1996, 88, 612-615.

8 M. T. Rautalahti, J. R. K. Virtamo, P. R. Taylor, O. P. Heinonen, D. Albanes, J. K. Haukka, B. K. Edwards, P. A. Kärkkäinen, R. Z. Stolzenberg-Solomon and J. Huttunen, The effects of supplementation with $\alpha$-tocopherol and $\beta$-carotene on the incidence and mortality of carcinoma of the pancreas in a randomized, controlled trial, Cancer, 1999, 86, 37-42.

9 D. Albanes, N. Malila, P. R. Taylor, J. K. Huttunen, J. Virtamo, B. K. Edwards, M. Rautalahti, A. M. Hartman, M. J. Barrett, P. Pietinen, T. J. Hartman, P. Sipponen, K. Lewin, L. Teerenhovi, P. Hietanen, J. A. Tangrea, M. Virtanen and O. P. Heinonen, Effects of supplemental $\alpha$-tocopherol and $\beta$-carotene on colorectal cancer: results from a controlled trial (Finland), Cancer Causes Control, 2000, 11, 197-205.

10 J. Virtamo, B. K. Edwards, M. Virtanen, P. R. Taylor, N. Malila, D. Albanes, J. K. Huttunen, A. M. Hartman, P. Hietanen, H. Mäenpää, L. Koss, S. Nordling and O. P. Heinonen, Effects of supplemental $\alpha$-tocopherol and $\beta$-carotene on urinary tract cancer: incidence and mortality in a controlled trial (Finland), Cancer Causes Control, 2000, 11, 933-939.

11 S. L. Hansen, S. Purup and L. P. Christensen, Bioactivity of falcarinol and the influence of processing and storage on its content in carrots (Daucus carota L.), J. Sci. Food Agric., 2003, 83, 1010-1017.
12 U. Kidmose, S. L. Hansen, L. P. Christensen, M. Edelenbos and R. Nørbæk, Effects of genotype, processing, storage, and root size on bioactive compounds (carotenoids, polyacetylenes, 6-methoxymellein) in organically grown carrots (Daucus carota L.), J. Food Sci., 2004, 69, S388S394.

13 L. P. Christensen and K. Brandt, Bioactive polyacetylenes in food plants of the Apiaceae family: occurrence, bioactivity and analysis, J. Pharm. Biomed. Anal., 2006, 41, 683-693.

14 L. P. Christensen and S. Kreutzmann, Determination of polyacetylenes in carrot roots (Daucus carota L.) by highperformance liquid chromatography coupled with diode array detection, J. Sep. Sci., 2007, 30, 483-490.

15 C. Dawid, F. Dunemann, W. Schwab, T. Nothnagel and T. Hofmann, Bioactive $\mathrm{C}_{17}$-polyacetylenes in carrots (Daucus carota L.): current knowledge and future perspectives, J. Agric. Food Chem., 2015, 63, 9211-9222.

16 B. T. Metzger, D. M. Barnes and J. D. Reed, Purple carrot (Daucus carota L.) polyacetylenes decrease lipopoly-saccharide-induced expression of inflammatory proteins in macrophage and endothelial cells, J. Agric. Food Chem., 2008, 56, 3554-3560.

17 L. P. Christensen, Aliphatic $\mathrm{C}_{17}$-polyacetylenes of the falcarinol type as potential health promoting compounds in food plants of the Apiaceae family, Recent Pat. Food, Nutr. Agric., 2011, 3, 64-77.

18 D. P. Killeen, C. E. Sansom, R. E. Lill, J. R. Eason, K. C. Gordon and N. B. Perry, Quantitative Raman spectroscopy for the analysis of carrot bioactives, J. Agric. Food Chem., 2013, 61, 2701-2708.

19 G. Appendino, S. Tagliapietra, G. M. Nano and V. Picci, An antiplatelet acetylene from the leaves of Ferula communis, Fitoterapia, 1993, 64, 179.

20 J. Alanko, Y. Kurahashi, T. Yoshimoto, S. Yamamoto and K. Baba, Panaxynol, a polyacetylene compound isolated from oriental medicines, inhibits mammalian lipoxygenases, Biochem. Pharmacol., 1994, 48, 1979-1981.

21 Y. Fujimoto, S. Sakuma, S. Komatsu, D. Sato, H. Nishida, Y. Q. Xiao, K. Baba and T. Fujita, Inhibition of 15-hydroxyprostaglandin dehydrogenase activity in rabbit gastric antral mucosa by panaxynol isolated from oriental medicines, J. Pharm. Pharmacol., 1998, 50, 1075-1078.

22 H. Matsunaga, M. Katano, H. Yamamoto, H. Fujito, M. Mori and K. Takata, Cytotoxic activity of polyacetylene compounds in Panax ginseng C. A. Meyer, Chem. Pharm. Bull., 1990, 38, 3480-3482.

23 Y. Fujimoto, M. Satoh, N. Takeuchi and M. Kirisawa, Cytotoxic acetylenes from Panax quinquefolium, Chem. Pharm. Bull., 1991, 39, 521-523.

24 M. W. Bernart, J. H. Cardellina II, M. S. Balaschak, M. Alexander, R. H. Shoemaker and M. R. Boyd, Cytotoxic falcarinol oxylipins from Dendropanax arboreus, J. Nat. Prod., 1996, 59, 748-753.

25 M. Miyazawa, H. Shimamura, R. C. Bhuva, S. Nakamura and H. Kameoka, Antimutagenic activity of falcarindiol 
from Peucedanum praeruptorum, J. Agric. Food Chem., 1996, 44, 3444-3448.

26 Y. C. Kuo, Y. L. Lin, C. P. Huang, J. W. Shu and W. J. Tsai, A tumor cell growth inhibitor from Saposhnikovae divaricate, Cancer Invest., 2002, 20, 955-964.

27 C. Zidorn, K. Johrer, M. Ganzera, B. Schubert, E. M. Sigmund, J. Mader, R. Greil, E. P. Ellmerer and H. Stuppner, Polyacetylenes from the Apiaceae vegetables carrot, celery, fennel, parsley, and parsnip and their cytotoxic activities, J. Agric. Food Chem., 2005, 53, 25182523.

28 J. F. Young, S. J. Duthie, L. Milne, L. P. Christensen, G. G. Duthie and C. S. Bestwick, Biphasic effect of falcarinol on Caco-2 cell proliferation, DNA damage, and apoptosis, J. Agric. Food Chem., 2007, 55, 618-623.

29 S. Purup, E. Larsen and L. P. Christensen, Differential effects of falcarinol and related aliphatic $\mathrm{C}_{17}$-polyacetylenes on intestinal cell proliferation, J. Agric. Food Chem., 2009, 57, 8290-8296.

30 S. Sun, G. J. Du, L. W. Qi, S. Williams, C. Z. Wang and C. S. Yuan, Hydrophobic constituents and their potential anticancer activities from Devil's Club (Oplopanax horridus Miq.), J. Ethnopharmacol., 2010, 132, 280-285.

31 R. G. Zaini, K. Brandt, M. R. Clench and C. L. Le Maitre, Effects of bioactive compounds from carrots (Daucus carota L.), polyacetylenes, beta-carotene and lutein on human lymphoid leukaemia cells, Anticancer Agents Med. Chem., 2012, 12, 640-652.

32 M. Kobæk-Larsen, L. P. Christensen, W. Vach, J. RitskesHoitinga and $\mathrm{K}$. Brandt, Inhibitory effects of feeding with carrots or (-)-falcarinol on development of azoxymethaneInduced preneoplastic lesions in the rat colon, J. Agric. Food Chem., 2005, 53, 1823-1827.

33 K. E. Bae, Y. W. Choi, S. T. Kim and Y. K. Kim, Components of rhizome extract of Cnidium officinale Makino and their in vitro biological effects, Molecules, 2011, 16, 8833-8847.

34 W. Heydenreuter, E. Kunold and S. A. Sieber, Alkynol natural products target ALDH2 in cancer cells by irreversible binding to the active site, Chem. Commun., 2015, 51, 15784-15787.

35 E. Paulsen, L. P. Christensen and K. E. Andersen, Dermatitis from common ivy (Hedera helix L. subsp. helix) in Europe: past, present, and future, Contact Dermatitis, 2010, 62, 201-209.

36 C. E. DeSantis, C. C. Lin, A. B. Mariotto, R. L. Siegel, K. D. Stein, J. L. Kramer, R. Alteri, A. S. Robbins and A. Jemal, Cancer treatment and survivorship statistics, 2014, CA-Cancer J. Clin., 2014, 64, 252-271.

37 WCRF, WCRF/AICR Systematic Literature Review Continuous Update Project Report: The associations between food, nutrition and physical activity and the risk of colorectal cancer, Washington DC: WCRF and American Institute for Cancer Research, 2010, pp. 1-855.

38 R. B. El-Houri, D. Kotowska, K. B. Christensen, S. Bhattacharya, N. Oksbjerg, G. Wolber, K. Kristiansen and L. P. Christensen, Polyacetylenes from carrots (Daucus carota) improve glucose uptake in vitro in adipocytes and myotubes, Food Funct., 2015, 6, 2135-2144.

39 L. Schmiech, C. Alayrac, B. Witulski and T. Hofmann, Structure determination of bisacetylenic oxylipins in carrots (Daucus carota L.) and enantioselective synthesis of falcarindiol, J. Agric. Food Chem., 2009, 57, 11030-11040.

40 A. Czepa and T. Hofmann, Structural and sensory characterization of compounds contributing to the bitter off-taste of carrots (Daucus carota L.) and carrot puree, J. Agric. Food Chem., 2003, 51, 3865-3873.

41 M. Leonti, L. Casu, S. Raduner, F. Cottiglia, C. Floris, K. H. Altmann and J. Gertsch, Falcarinol is a covalent cannabinoid CB1 receptor antagonist and induces pro-allergic effects in skin, Biochem. Pharmacol., 2010, 79, 1815-1826.

42 R. P. Bird, Observation and quantification of aberrant crypts in the murine colon treated with a colon carcinogen: preliminary findings, Cancer Lett., 1987, 37, 147-151.

43 R. P. Bird, Role of aberrant crypt foci in understanding the pathogenesis of colon cancer, Cancer Lett., 1995, 93, 55-71.

44 F. Marotta, Y. Naito, E. Minelli, H. Tajiri, J. Bertuccelli, C. C. Wu, C. H. Min, P. Hotten and E. Fesce, Chemopreventive effect of a probiotic preparation on the development of preneoplastic and neoplastic colonic lesions: an experimental study, Hepatogastroenterology, 2003, 50, 1914-1918.

45 D. E. Corpet and F. Pierre, How good are rodent models of carcinogenesis in predicting efficacy in humans? A systematic review and meta-analysis of colon cancer chemoprevention in rats, mice and humans, Eur. J. Cancer, 2005, 41, 1911-1922.

46 B. S. Reddy, Studies with azoxymethane-rat preclinical model for assessing colon tumor development and chemoprevention, Environ. Mol. Mutagen., 2004, 44, 26-35.

47 R. E. Rudolph, J. A. Domonitz, J. W. Lampe, L. Levy, P. Qu, S. S. Li, P. D. Lampe, M. P. Bronner and P. D. Potter, Risk factors for colorectal cancer in relation to number and size of aberrant crypt foci in humans, Cancer Epidemiol. Biomarkers Prev., 2005, 14, 605-608.

48 N. Metz, A. Lobstein, Y. Schneider, F. Gossé, R. Schleiffer, R. Anton and F. Raul, Suppression of azoxymethaneinduced preneoplastic lesions and inhibition of cyclooxygenase- 2 activity in the colonic mucosa of rats drinking a crude green tea extract, Nutr. Cancer, 2000, 38, 60-64.

49 Y. Kishimoto, K. Yashima, T. Morisawa, G. Shiota, H. Kawasaki and J. Hasegawa, Effects of cyclooxygenase-2 inhibitor NS-398 on APC and c-myc expression in rat colon carcinogenesis induced by azoxymethane, J. Gastroenterol., 2002, 37, 186-193.

50 R. M. Prior, N. H. Lundgaard, M. E. Light, G. I. Stafford, J. van Staden and A. K. Jäger, The polyacetylene falcarindiol with COX-1 activity isolated from Aegopodium podagraria L., J. Ethnopharmacol., 2007, 113, 176-178.

51 Y. R. Um, C. S. Kong, J. I. Lee, Y. A. Kim, T. J. Nam and Y. Seo, Evaluation of chemical constituents from Glehnia littoralis for antiproliferative activity against HT-29 human colon cancer cells, Process Biochem., 2010, 45, 114-119. 
52 M. Karin and F. R. Greten, NF-kappaB: linking inflammation and immunity to cancer development and progression, Nat. Rev. Immunol., 2005, 5, 749-759.

53 D. G. Crosby and A. Aharonson, The structure of carotatoxin, a natural toxicant from carrot, Tetrahedron, 1967, 23, 465-472.
54 K. Uwai, K. Ohashi, Y. Takaya, T. Ohta, T. Tadano, K. Kisara, K. Shibusawa, R. Sakakibara and Y. Oshima, Exploring the structural basis of neurotoxicity in $\mathrm{C}_{17}$-polyacetylenes isolated from water hemlock, J. Med. Chem., 2000, 43, 4508-4515. 